\title{
Enhancing Higher Education Student Class Attendance through Gamification
}

\author{
Robert Pinter ${ }^{1}$, Sanja Maravić Čisar ${ }^{1}$, Zoltán Balogh ${ }^{2}$ and \\ Helena Manojlović ${ }^{1}$
}

${ }^{1}$ Subotica Tech - College of Applied Sciences, Marka Oreškovića 16, 24000

Subotica, Serbia

${ }^{2}$ Constantine the Philosopher University in Nitra, 94974, Nitra, Trieda Andreja

Hlinku 1. Nitra, Slovakia

e-mail: pinter.robert@vts.su.ac.rs, sanjam@vts.su.ac.rs, zbalogh@ukf.sk, helena@vts.su.ac.rs

\begin{abstract}
This paper presents an electronic system for tracking students' attendance. "BeHere" was implemented at Subotica Tech - College of Applied Sciences, introducing gamification elements into class attendance tracking. Given that the first year of their studies in higher education is the most crucial time period, it is vital that students are motivated to attend classes regularly. Class attendance is frequently seen as the prime marker of students' persistence: lower attendance indicates a higher risk of dropout. The gamification module of the system is used to improve student engagement, motivation, attendance, and academic performance. Based on the research results, it is evident that the tested gamification module motivated students to attend classes more regularly during the 2018/19 school year as compared with the previous year.
\end{abstract}

Keywords: higher education; class attendance; gamification

\section{Introduction}

Setting out on an academic career poses a serious challenge for students, especially considering the significant changes from secondary school to university [1]. Their adaptation to the novel circumstances in the first year of higher education is vital [2]. Class attendance is frequently seen as the prime marker of students' persistence and results, while absenteeism is taken as an indicator of the risk of dropout [3, 4]. In this regard, according to [5], there is a great need for motivating students through "an ethos of attendance" as a means of integrating first-year students into academia. 
Bruinsma and Jansen stated [6], "the first year is especially important as it serves as an orientation to the remainder of the study and selects those students who are willing to persist".

There is a wide spectrum of factors influencing the students' successful adaption to the university lifestyle and their academic achievement during the first two semesters. On the one hand, factors such as the individual student's age, gender, motivation, and personality, as well as previous (secondary school) performance and efficient study techniques must be taken into consideration. On the other hand, academic aspects including the study programme structure, curriculum design, educational environment, integration activities and social inclusion must also be taken into account [7].

Numerous studies have been conducted into this issue and the central conclusion is that there is a considerable correlation between regular attendance and study results $[4,8,9]$. Halpern [10] explored the relationship between going to classes and passing exams using correlation analysis and determined that a significant moderately positive relationship exists $(r=0.50, p<0.001)$. Further, Halpern examined whether or not the effect of attendance on academic achievement is causal by applying regression analysis. In Halpern's view attendance has a significant positive effect $(\mathrm{r}=0.40, \mathrm{p}<0.001)$.

There are also, however, authors who express their doubts regarding how attendance will affect the study results. To name just one example, Eisen et al. [11] studied the issue of the importance of attendance versus academic performance among second-year medical students. Based on their results they deduced that not going to active and engaging lectures did not negatively affect the results. In order for informed policy decisions to be made, there is a need for a close examination of the effect of attendance. The debate mostly revolves around whether or not it is the task of the higher education institutions to regulate attendance, e.g. by defining minimum attendance requirements. Several studies highlighted that students may not oppose interventions; in fact, they are likely to see these regulations as indications of care and paying attention to the university's side [12]. However, certain authors may not agree. St. Clair [13] offered arguments against compulsory attendance, her reasoning being that the currently offered studies do not provide enough justification for such policies. Further, she argues that other, also significant factors influencing study success are thereby disregarded. The goal, in her view, is that students should wish to attend, instead of forcing them to sit in classes through stark regulations. Students should feel being in control, which would, in turn, stimulate them to attend regularly.

Educators still, by and large, expect their students to be present in class. The general assumption is that students will fail to make advancements in knowledge acquisition and comprehension of the study material if they are not in the class so as to enjoy the classroom experience. However, it must be taken into consideration that those young people studying engineering technologies today 
have grown up in a starkly different learning environment if compared with the classroom of two decades ago. The way they access information and use digital media means that the students have almost instant access via the Internet. The question arises whether or not students will react to this greater connectivity in the same way as to the "older" teaching methods. Modern technology enables current students to learn, access information and interact with their peers even if they do not share the same physical space or visit the library in person. In short, the students of today simply do not have the same need to actually be sitting in their classes just so they could be successful.

Consequently, one may ask why it is that, given access to all digital learning resources, students are still 'tied' to the classroom? In order to be able to answer this question, it must be acknowledged that apart from an altered learning environment, today's engineering students need to gain new technical skills in order to hold successful jobs in the engineering field. Today's tasks require technical engineers to have technical skills and problem-solving skills, as well as communication skills, critical thinking and commitment skills. These skills can only be acquired within the classroom, in active learning environments such as project or problem-based learning.

\section{Motivation through Gamification}

This section highlights the motivational options which help in stimulating students to spend more time voluntarily in their classes and actively participate in their education. At Subotica Tech - College of Applied Sciences, the lecturers take different approaches in order to reward the students' continued attendance. The main approach is that students' absence has to have negative consequences. The class requirements do not include 'rewards' for actually attending and actively participating, only 'punishment' for missing the classes. Some professors believe that it is the students' responsibility whether or not they wish to attend lectures. These educators do not track student presence, the class requirements also do not indicate any negative consequences for either attending or missing classes.

If one feels 'motivated' it refers to the inherent urge to take action. Thus, if a person feels no stimulation towards taking action, they are likely to be seen as 'unmotivated'. The greater the student's motivation towards learning, the greater the likelihood that the student will engage in classes, which also means that the student has a greater chance of acquiring new knowledge.

People experience various types of motivation, while there are also different levels and orientations of these motivations. For instance, a given student may feel exceedingly stimulated to write homework simply because he or she is curious and interested. However, this motivation may also be due to their drive to prove themselves to their teacher or parent. Another form of motivation may be the fact 
that the student is aware of the potential usefulness or value of the new skills to be learned.

In Self-Determination Theory (STD) Deci and Ryan presented a great number of motivations driving behaviour and performance [14]. For the purposes of this study, the present authors have use STD's elucidation of motivation processes to build our own system. STD define the continuum of four types of motivations (Figure 1).

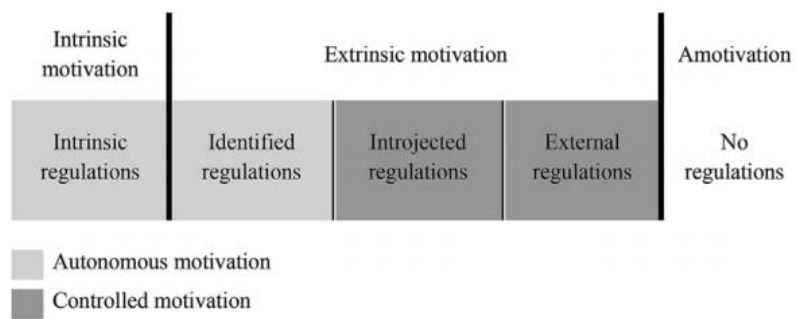

Figure 1

Types of motivation

Intrinsic motivation is, as the definition suggests, "doing something because it is inherently interesting or enjoyable", while extrinsic motivation means "doing something because it leads to a separable outcome".

Educators have become more and more aware of the significance of intrinsic motivation [15]. Given that intrinsic motivation is likely to lead to high-quality learning and creativity, it is vital for those factors and forces that foster as opposed to hampering it.

Extrinsic motivation, though, is no less crucial and must, therefore, be thoroughly understood by educators. Not all lectures and activities are instantly seen as 'interesting' or 'enjoyable', so students must be enticed and engaged by various the extrinsic motivation techniques $[16,17]$.

Gamification is defined as using game elements and game design techniques in non-game contexts. The overall goal is to integrate intrinsic motivation with extrinsic motivation so as to trigger students' engagement and motivation to participate actively [18]. Numerous studies highlighted the positive learning outcomes of using gamification [19], though, there are also papers that presented mixed results or even negative effects [20].

The gamification module created by the author's implements points, badges, and a leader-board (PBL) as game elements in the rewarding system. The aim is for the student to receive feedback from the educator in the form of these elements, which will make them more aware of their advancement and active participation in their own learning process. The PBL system also serves as a method of comparison for each other's achievement. The following section outlines the application of gamification in the system tracking class attendance. 


\section{Presentation of Electronic System for Tracking Attendance}

Tracking attendance is a crucial activity on all levels of educational institutions, from elementary school to university. The teacher needs to be able to trace the classroom presence as well as activities of any given student. If a particular class is attended by a large number of students, the teacher would generally resort to the age-old method of roll call and marking attendance on paper. However, this is both tedious and time-consuming, thus a novel method of tracking attendance has to be introduced.

In this section, we present an electronic system with the task to automate the tracking of class attendance. Automation is vital since it ensures the fact and efficient task performance. The task itself is anything but trivial. The teacher spends (in fact, 'loses') a considerable amount of valuable teaching time on recording class presence. After having recorded who is present in a given class, the teacher must then archive the collected data along with the other class information. Without digitalization, trying to trace the overall class activity of a single student becomes quite a challenge, and manual data input is even more time-consuming. The time needed for tracking and evaluating class attendance only increases with the rising number of students in a group or on a specific course.

Electronic tracking of class attendance enables the teacher to quickly generate an attendance report for an individual student on a given course. The data is stored in a database, which can be accessed by teachers, institutional management, as well as in certain cases the students themselves. The teacher may use the gathered data to influence the educational process.

Management of a given educational institution may analyze the data on class attendance and make the following deductions:

- which course has an attendance problem - a piece of information that may be in relation to the quality evaluation of the given course;

- the rate of student number fluctuation;

- whether or not the classes are held as indicated in the official class time table.

Generating an attendance report enables the teachers and/or management to quickly find ways to identify and remove the causes for low attendance. Subotica Tech - College of Applied Sciences almost regularly experiences a dissipation rate of about $25 \%$, with a quarter of its students 'disappearing' by the start of the January exam period. There is a considerable need for a system that could offer daily feedback on student attendance, i.e. absenteeism, so as to detect those students who are likely to constitute the $25 \%$, and identify the causes for the 'disappearance'. One of these causes insufficient pre-knowledge in students, 
which makes it difficult for them to follow the classes. A further cause is that college students come from vastly different educational backgrounds, from a wide range of secondary schools that may not be compatible with the technical profile of the College. Thus, it may happen, for instance, that high school students from the Medical secondary school or Chemical Vocational school actually enroll in Subotica Tech, but lack satisfactory background knowledge in the technicaltechnological field studies to be able to successfully complete this technical college. All parties would benefit from a system that would allow the identification of the missing background knowledge and opportunity through, e.g. short courses to attain the level of the general class so as to include these students, too, in the successful educational process.

\subsection{Hardware Modul}

Prior to realizing this project of an electronic attendance tracking system, a number of similar systems were analyzed. This paragraph details the features and possibilities offered by these analyzed systems, as well as the method of identification they use. At Texas State University a web application is implemented for displaying a given individual's campus activities. Identification happens via ID card and card reader [21]. The second example is the 'Creatrix Campus Attendance Management System', which includes not only student identification in the different classrooms where they listen to lectures (and engage in different learning activities), but also analyzes the movements and activities of an individual student. Based on the pattern of activities, i.e. times of absence, the system automatically suggests various measures to improve the situation, setting attainable goals for those students, all aimed at motivating the individual to attend classes regularly [22]. Northern Arizona University uses an RFID method for student identification. The ID process happens via card readers that are installed in the lecture halls where the students attend the lectures and in locations where they engage in other educational activities (classrooms, computer science laboratories, etc.). This enables fast and efficient identification even for large numbers of students [23].

The implementation of the previously described systems incurs considerable costs. The proper operation of the system requires the installation of card readers in all classrooms, distribution of cards among students and the creation of a central information system that stores and displays information (i.e. server with a database). The overall cost of implementing this tracking system at Northern Arizona University was close to $\$ 85.000$. During the design process of the class attendance tracking system for students at Subotica Tech, the following requirements needed to be met: all the main functions had to be included tracking attendance, recording and displaying information on the presence, moreover, the system needed to be inexpensive both in terms of realization and 
maintenance. This goal was achieved in the following way according to the scheme on Figure 2:

- attendance identification happens via smartphone, thereby eliminating the costs of ID, NFC or RFID cards;

- identification is confirmed by a microprocessor system whose cost does not exceed $€ 30$. The device is small, easy to carry into class and is functional in classrooms without Internet access, as well;

- free software solutions were found for the webserver and database server.

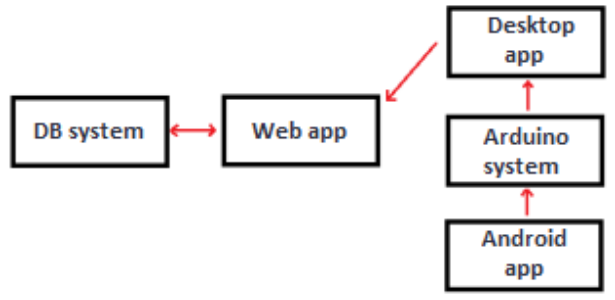

Figure 2

Block scheme of the system

The electronic class attendance tracking system is composed of several units:

Android application. The student can log in via an Android application for a mobile phone, which identifies him or her. Identification is easy, it is a simple click on a button. As soon as the application sends the student's data to the Arduino system, the user receives confirmation on successful identification. The application only sends basic information, most importantly, the student's index number. Detailed user information of the student to be identified is entered during the primary installation of the application and cannot be altered later (Figure 3).

Arduino platform. The characteristics of the Arduino NANO microprocessor platform are as follows: 12 digital inputs/outputs D2-D13; 8 analogue inputs A0 A7; 1 TTL serial port - RX / TX; 6 PWM port; uses Atmel Atmega328P-AU microcontroller (Figure 2). The Arduino and the mobile application communicate via Bluetooth connection using a HC-05 module (Figure 3).

Desktop application for controlling Arduino via microprocessor (Figure 4). An application has to be installed on the teacher's PC which can control the Arduino platform. The process of attendance tracking is described below. 

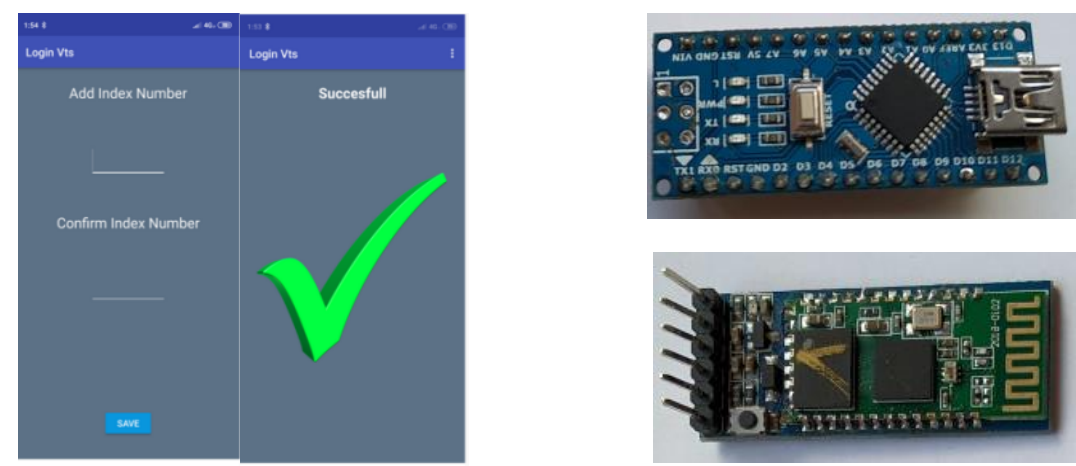

Figure 3

Mobil application interface and Arduino and Bluetooth module

The Arduino microprocessor is connected to the teacher's PC through one of the USB ports, and the teacher runs the application, enters the relevant data (select teacher's name and course title), then the PC initiates the connection to the Arduino. After clicking on the Start button, triggers the process of tracking student attendance. The system then makes connections with all the applications running on the students' mobile devices until the teacher clicks on the Stop button.

The students run the application on their own mobile devices and by clicking on the button, start log on to the system. Given that Bluetooth connection can only happen between the two devices at the same time, the link between student mobile devices and the Arduino occurs sequentially. The time required for identifying each student is approximately 1 second. Prior to the identification process, it is necessary to pair the students' mobile devices with the Arduino system. This is a short procedure that is performed only once, at the start of the semester.

Once the teacher's PC successfully receives the data, the students' names are listed. By clicking Stop, the teacher discontinues the process of tracking attendance. By clicking Upload, the collected data is sent to the server application. The desktop application is both fast and easy to handle.

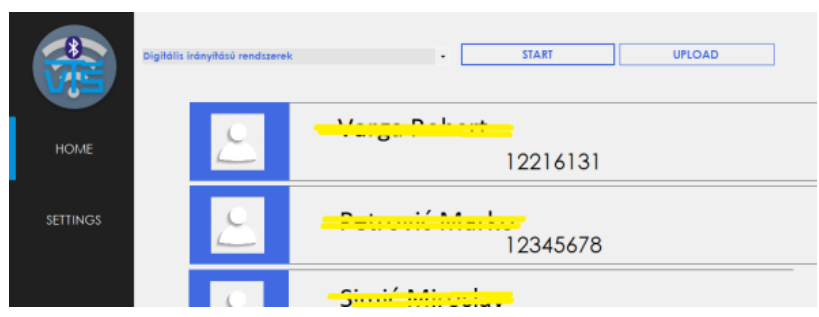

Figure 4

Desktop application 
The system is capable of identifying up to 60 students (i.e. their devices) in one minute if located within a radius of 10 meters. The relatively limited range of the Bluetooth connection prevents students from cheating the system by trying to confirm their presence from any other classroom except where the class is held, even within the college building. Due to privacy issues, the students' names are presented here in strike-through marked with a yellow line.

Web application. The server application's main task is to receive and store data in the database. The application has access restriction, so only the registered teachers can log on to the system. After the login, the teacher has access to data related to his/her classes. The teacher can select which class attendance data to be displayed. The data is presented in a table, where the rows signify the students, while the columns are the weeks. At Subotica-Tech one semester is composed of 15 weeks. Since every course can have either a lecture or exercise part or in general, both, this means that the teacher can register attendance at one course for one student a maximum of 30 times (twice a week). The next figure (Figure 5) shows the table for one class with the students' names and their attendance in weeks.

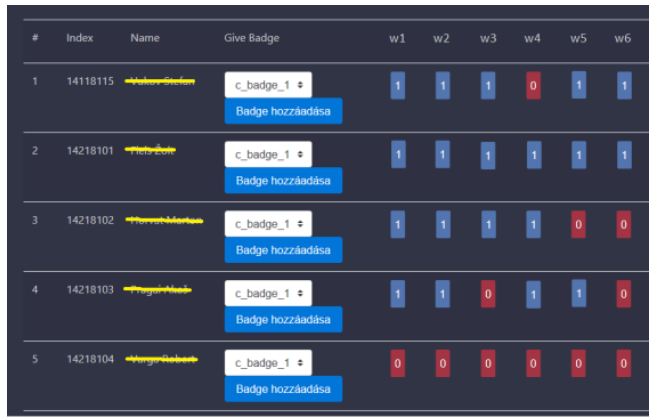

Figure 5

Students' attendance in weeks

The table shows which week the student was present in class (blue rectangles marked with ' 1 ') and which week the given student missed this specific class (red rectangle marked with ' 0 '). With this "table view," the teacher immediately has an overview of how many students attend a specific class, and which weeks they attended the class.

This table is also used for the manual recording of attendance registration: by clicking on the red rectangle it becomes blue. This option is important because there are cases when the student in unable to register using his/her phone, for example, if they forgot to bring their mobile phone to the school, or if the phone has no Android OS, etc. This is also the page where the teacher can assign badges to the student. 


\subsection{Gamification Module}

The suggested class attendance tracking system automates the process which teachers have so far been handling manually as an integral part of their teaching activities.

Gamification, and it's awarding nature is just one of the methods used in trying to motivate students to be more active in their own educational process. The idea that was realized in this project was to create a so-called 'high score list' (or leaderboard) of ranking the 'best' students. The list is formed based on the following criteria:

- Number of class attendances on courses in a given academic year for a specific student;

- Points to be gained through extra tasks that the teacher deems worth awarding points for.

The 'high score list' contains the student's name, the overall points collected in the two ways described above (see Figure 6). The badges form a visualization of the points given by the teachers for various activities completed by the student. The system currently contains nine badges. Each badge has its own defined value and graphical representation. The first badge is the 'bronze badge' without any stars. The next two are also 'bronze' ones, yet with stars added. This is followed by the 'silver badge' and 'gold badge' in the same distribution.

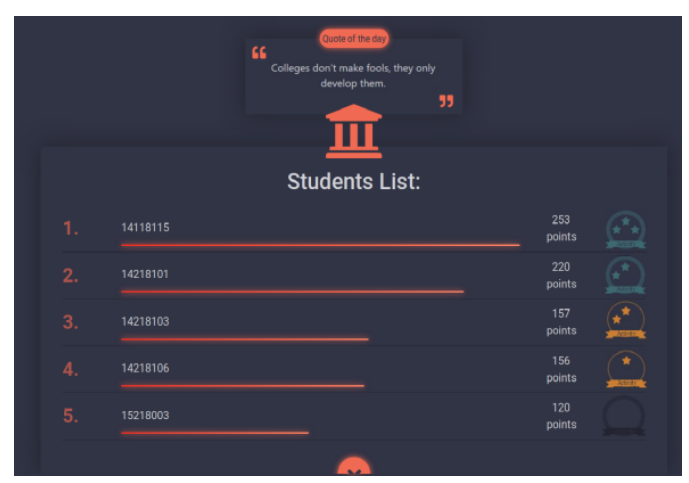

Figure 6

"High Score" list based on the collected points

\section{Research}

The basic hypothesis is that applying gamification increases students' motivation to attend classes. Accordingly, the aim is to test the following hypothesis:

H1: Gamification will increase students' attendance to classes. 
In addition to this main hypothesis, the following hypotheses were also stated:

$\mathrm{H} 2$ : The leader-board is a motivating element for students.

H3: Badges awarded for active participation in classes are seen as a motivating element.

Hypothesis $\mathrm{H} 1$ will be tested by analyzing the data of students' regular class attendance when their attendance was recorded using the "BeHere" system and when their attendance was checked in the traditional way (calling out students by name or collecting students' signatures).

As stated earlier, Subotica Tech uses the "BeHere" system to record students' class attendance. It was initially used in the academic year 2018/19. The collected data served as the basis for testing the hypothesis $\mathrm{H} 1$.

The attendance data forming the basis for analysis was collected among the firstyear students in the autumn and spring semesters of two academic years, 2017/18 and 2018/19. In both autumn semesters, the course whose attendance was tracked was the English language, while in the spring semesters the platform of tracking attendance was the informatics course Object-oriented programming. In the first year of testing, during the academic year 2017/18, attendance tracking was performed in the classic form, by the teacher, through roll call or having the students sign an attendance sheet. These students were the control group. In the second year of the experiment, in 2018/19, attendance tracking was performed using the "BeHere" system with its integrated gamification elements. These students formed the experimental group.

The higher education system in Serbia defines the semester as a study period of 15 weeks. Based on this, class attendance is recorded both for lectures and practices, thus for a given course, the student can ideally be recorded twice a week as having attended classes. This leads to an overall number of 30 times during one semester, for one course, when the student could be recorded as attending classes.

The following distribution was drawn up based on how many times they attended the classes:

- Group I - students missed $1 / 3$ or less of all the classes (1/3 of the 30 classes in total, including both lectures and practices) during the semester,

- Group II - students missed between $1 / 3$ and 2/3 of the classes,

- Group III - students missed more than $2 / 3$ of the overall number of classes.

During the academic year 2017/18, the total number of students whose attendance was tracked was $358(\mathrm{~N}=196$ for the course English language and $\mathrm{N}=162$ for Object-oriented programming). The total number of students whose class attendance was tracked in 2018/19 was $340(\mathrm{~N}=185$ for English language and $\mathrm{N}=165$ for OOP). 
Only the students meeting one of the following criteria were included in the process of analysis: a) students who attended at least one lecture, b) attended at least one practice, or c) handed in at least one homework project, or taken one test during the term. Taking all these into consideration, the distribution of the overall student participant number was:

- during the academic year 2017/18, there were overall 288 students, $14 \%$ of them female and $86 \%$ male ( $\mathrm{N}=160$ for English language and $\mathrm{N}=128$ for OOP)

- during the academic year 2018/19, there were overall 282 students, $17 \%$ of them female and $83 \%$ male ( $\mathrm{N}=150$ for English language and $\mathrm{N}=132$ for OOP)

Table 1 presents the distribution of the number of participants based on how often the students attended classes, categorized into three groups as described above:

Table 1

The distribution of the number of participants based on how often the students attended classes

\begin{tabular}{|l|c|c|c|c|}
\cline { 2 - 5 } \multicolumn{1}{c|}{} & \multicolumn{2}{c|}{ English language } & \multicolumn{2}{c|}{ OOP } \\
\hline \multirow{2}{*}{} & Control group & $\begin{array}{c}\text { Experimental } \\
\text { group }\end{array}$ & Control group & $\begin{array}{c}\text { Experimental } \\
\text { group }\end{array}$ \\
\hline $\mathrm{x}^{*}<1 / 3$ & 57 & 65 & 45 & 55 \\
\hline $1 / 3<\mathrm{x}<2 / 3$ & 66 & 60 & 54 & 60 \\
\hline $\mathrm{x}>2 / 3$ & 37 & 25 & 29 & 17 \\
\hline & 160 & 150 & 128 & 132 \\
\hline
\end{tabular}

*where $\mathrm{x}$ is the number of absences

One of the requirements during the semester is, in fact, class attendance, for which students are awarded a set number of points. For the courses in question, English language, and Object-oriented programming, the course coordinators opted not to award any points for regular class attendance.

An independent-samples t-test was conducted to compare the number of absences for the control and experimental group based on the number of absences for the course English language and Object-oriented programming. The results for each of the three groups are shown in Table 2, 3 and 4 for the course English language and for the Object -oriented programming are shown in Table 5, 6 and 7.

Table 2

Group I statistics for absenteeism less than $1 / 3$ of the total number of the classes for the course English language

\begin{tabular}{|l|c|c|c|c|}
\hline & $\mathrm{N}$ & Mean & Std. Deviation & Variance \\
\hline Control group & 57 & 5.9123 & 2.9897 & 8.9386 \\
\hline Experimental group & 69 & 4.8308 & 2.7532 & 7.5803 \\
\hline $\mathbf{t}$ & \multicolumn{5}{|c|}{$\mathbf{2 . 0 7 9 5}$} \\
\hline Degrees of freedom & \multicolumn{5}{|c|}{$\mathbf{1 . 9 8}$} \\
\hline Critical value & \multicolumn{5}{|c|}{} \\
\hline
\end{tabular}


The experimental group students $(\mathrm{M}=4.8308, \mathrm{SD}=2.7532)$ had fewer absences than the students from the control group ( $M=5.9123, \mathrm{SD}=2.9897)$. The means of control and experimental group are significantly different at $\mathrm{p}<0.05$.

Table 3

Group II statistics for absenteeism greater than $1 / 3$ and less than $2 / 3$ of the total number of the classes for the course English language

\begin{tabular}{|l|c|c|c|c|}
\hline & $\mathrm{N}$ & Mean & Std. Deviation & Variance \\
\hline Control group & 66 & 16.0303 & 2.8337 & 8.0298 \\
\hline Experimental group & 60 & 14.9333 & 2.887 & 8.3345 \\
\hline $\mathbf{t}$ & \multicolumn{5}{|c|}{$\mathbf{2 . 1 5 0 9}$} \\
\hline Degrees of freedom & \multicolumn{5}{|c|}{$\mathbf{1 . 9 8}$} \\
\hline Critical value & \multicolumn{5}{|c|}{} \\
\hline
\end{tabular}

The experimental group students $(\mathrm{M}=14.93, \mathrm{SD}=2.887)$ had fewer absences than the students from the control group $(\mathrm{M}=16.0303, \mathrm{SD}=2.8337)$. The means of control and experimental group are significantly different at $\mathrm{p}<0.05$.

Table 4

Group II statistics for absenteeism greater than $2 / 3$ of the total number of the classes for the course

English language

\begin{tabular}{|l|c|c|c|c|}
\hline & $\mathrm{N}$ & Mean & Std. Deviation & Variance \\
\hline Control group & 37 & 25.8378 & 2.5551 & 6.5285 \\
\hline Experimental group & 25 & 24.48 & 2.2383 & 5.01 \\
\hline $\mathbf{t}$ & \multicolumn{5}{|c|}{$\mathbf{2 . 1 5 5 4}$} \\
\hline Degrees of freedom & \multicolumn{4}{|c|}{$\mathbf{2}$} \\
\hline Critical value & \multicolumn{5}{|c|}{} \\
\hline
\end{tabular}

The experimental group students $(\mathrm{M}=24.48, \mathrm{SD}=2.2383)$ had fewer absences than the students from the control group $(\mathrm{M}=25.8378, \mathrm{SD}=2.5551)$. The means of control and experimental group are significantly different at $\mathrm{p}<0.05$.

Table 5

Group I statistics for absenteeism less than $1 / 3$ of the total number of the classes for the course OOP

\begin{tabular}{|l|c|c|c|c|}
\hline & $\mathrm{N}$ & Mean & Std. Deviation & Variance \\
\hline Control group & 45 & 5.8889 & 3.0616 & 9.3737 \\
\hline Experimental group & 55 & 4.6182 & 2.7182 & 7.3886 \\
\hline $\mathbf{t}$ & \multicolumn{3}{|c|}{$\mathbf{2 . 1 9 6 9}$} \\
\hline Degrees of freedom & \multicolumn{5}{|c|}{$\mathbf{1 . 9 8 7}$} \\
\hline Critical value & \multicolumn{5}{|c|}{} \\
\hline
\end{tabular}


The experimental group students $(\mathrm{M}=4.6182, \mathrm{SD}=2.7182)$ had fewer absences than the students from the control group $(\mathrm{M}=5.8889, \mathrm{SD}=3.0616)$. The means of control and experimental group are significantly different at $\mathrm{p}<0.05$.

Table 6

Group II statistics for absenteeism greater than $2 / 3$ of the total number of the classes for the course OOP

\begin{tabular}{|l|l|l|c|c|}
\hline & $\mathrm{N}$ & Mean & Std. Deviation & Variance \\
\hline Control group & 54 & 16.2963 & 2.717 & 7.3823 \\
\hline Experimental group & 60 & 14.9333 & 2.887 & 8.3345 \\
\hline $\mathbf{t}$ & \multicolumn{5}{|c|}{$\mathbf{2 . 5 8 7 8}$} \\
\hline Degrees of freedom & \multicolumn{5}{|c|}{$\mathbf{1 . 9 8 4}$} \\
\hline Critical value & \multicolumn{5}{|c|}{} \\
\hline
\end{tabular}

The experimental group students $(\mathrm{M}=14.9333, \mathrm{SD}=2.887)$ had fewer absences than the students from the control group $(M=16.2963, \mathrm{SD}=2.717)$. The means of control and experimental group are significantly different at $\mathrm{p}<0.05$.

Table 7

Group II statistics for absenteeism greater than $2 / 3$ of the total number of the classes for the course OOP

\begin{tabular}{|l|c|c|c|c|}
\hline & N & Mean & Std. Deviation & Variance \\
\hline Control group & 29 & 25.8866 & 2.4105 & 5.8103 \\
\hline Experimental group & 17 & 24.3529 & 2.2344 & 4.9927 \\
\hline $\mathbf{t}$ & \multicolumn{5}{|c|}{$\mathbf{2 . 1 5 2 2}$} \\
\hline Degrees of freedom & 44 & $\mathbf{2 . 0 1 5}$ \\
\hline Critical value & \multicolumn{5}{|c|}{} \\
\hline
\end{tabular}

The experimental group students $(\mathrm{M}=24.3529, \mathrm{SD}=2.2344)$ had fewer absences than the students from the control group $(\mathrm{M}=25.8866, \mathrm{SD}=2.4105)$. The means of control and experimental group are significantly different at $\mathrm{p}<0.05$.

Based on the results of the analysis the hypothesis $\mathrm{H} 1$ is confirmed with a certainty of $95 \%$ and a risk of $5 \%$, that there is a statistically significant difference between the results of the control and experimental group, i.e. that gamification increased students' attendance to classes.

The experimental group was asked to complete a survey on gamification as a motivating factor in regular class attendance. We used Feedier to design and distribute the survey. The participants were informed about (a) the aim of the study, (b) the expected workload and (c) the need to have at least a moderate level of knowledge of the mentioned service. Also, potential respondents were assured of the anonymity and confidentiality of their responses. Attempts to complete the survey more than once on the same device were blocked. 
The survey was distributed among all students of the experimental group $(\mathrm{N}=282)$, 220 of whom managed to complete the survey in full (male: $85 \%$; female: 15\%; age: $M=20)$. The survey was composed using the guidelines found at [21]. The survey results are presented in Table 8 .

Table 8

Numerical feedback answers about the achievement badges $(\mathrm{N}=282) .(1=$ completely disagree, $2=$ somewhat disagree, $3=$ cannot say, $4=$ somewhat agree, $5=$ completely agree)

\begin{tabular}{|l|c|c|c|c|c|}
\hline Feedback item & 1 & 2 & 3 & 4 & 5 \\
\hline I found the badges motivating. & $6 \%$ & $10 \%$ & $10 \%$ & $\mathbf{4 6 \%}$ & $28 \%$ \\
\hline Badges were disturbing me in my studying. & $\mathbf{6 0 \%}$ & $20 \%$ & $10 \%$ & $8 \%$ & $2 \%$ \\
\hline $\begin{array}{l}\text { Trying to achieve badges affected my } \\
\text { behaviour. }\end{array}$ & $1 \%$ & $18 \%$ & $10 \%$ & $\mathbf{4 0 \%}$ & $31 \%$ \\
\hline The visual look of the badges was good. & $1 \%$ & $1 \%$ & $30 \%$ & $\mathbf{4 2 \%}$ & $26 \%$ \\
\hline $\begin{array}{l}\text { I was satisfied with the criteria for awarding } \\
\text { badges. }\end{array}$ & $1 \%$ & $3 \%$ & $15 \%$ & $\mathbf{4 8 \%}$ & $33 \%$ \\
\hline $\begin{array}{l}\text { I think that badges motivated me throughout } \\
\text { the semester. }\end{array}$ & $2 \%$ & $3 \%$ & $20 \%$ & $25 \%$ & $\mathbf{5 0 \%}$ \\
\hline
\end{tabular}

Based on the survey filled in by the students of the experimental group, it can be concluded that for most students, the badges had a motivating role in attending classes as regularly as possible. The majority of the students responded that they found the badges motivating and that they had an effect on their behaviour. Furthermore, the majority was satisfied with the criteria and visual appearance. Moreover, only a small minority of $10 \%$ reported that badges disturbed their work.

Students were given the opportunity to comment on the use of badges. The students' comments mostly revolved around the fact that collecting badges was like playing a game for them and that the desire to unlock a new badge was strong enough to motivate them to attend a class (especially when they needed only a few more points until the next badge). However, there were also comments stating that while at the beginning it was interesting to collect points and receive badges, it became tedious, they became quickly bored and no longer cared about attending classes in order to progress in winning new badges.

For a certain number of students, the badges held no significance and did not motivate them to attend classes regularly. The comments of this group of students highlighted that they would definitely attend classes because they were interested in the subject, regardless of whether or not they received badges regularly. Some of them commented that it was too childish to collect badges, that they came to classes when it was convenient for them and that they were not too concerned about winning some badges or not.

A certain number of the students believed that it would be much better, in fact, more motivating if they were given specific rewards in addition to badges, e.g. in 
the form of bonus points that they could redeem at a mid-term test or exam. Some of the students belonging to the second and third groups by the number of absences from classes were satisfied with the possibility that points could be obtained through badges which improved their position on the leader-board.

Students were pleased to be able to trace the performance of their peers through the badges and to compare themselves to the others. There were further suggestions to consider enabling the students to share their badge status on social networks, primarily to show off to their peers, or "tease" those who were ranked lower in the number of collected badges. Students also voiced their objection because it was not possible to pass the badges into the next academic year.

The students' views about the leader-board were very polarized. As a motivational element, the leader-board either had a weak effect or a highly positive effect, which is related to the personal preferences of the students. The students who have a competitive nature wanted their name to be ranked highest possible on the leader-board. For them, progress in the rankings during the semester was a motivating factor, they aimed for the top of the list. The second group consisted of students who did not care about ranking. Their views indicated the importance of the user's internal motivation for a successful outcome.

Table 9

Numerical feedback answers about the leader-board $(\mathrm{N}=282)$. ( $1=$ completely disagree, $2=$ somewhat disagree, $3=$ cannot say, $4=$ somewhat agree, $5=$ completely agree)

\begin{tabular}{|l|c|c|c|c|c|}
\hline Feedback item & 1 & 2 & 3 & 4 & 5 \\
\hline $\begin{array}{l}\text { The leader-board motivated me to attend } \\
\text { classes. }\end{array}$ & $11 \%$ & $14 \%$ & $8 \%$ & $\mathbf{4 5 \%}$ & $22 \%$ \\
\hline $\begin{array}{l}\text { The leader-board motivated me to arrive to } \\
\text { class on time. }\end{array}$ & $9 \%$ & $7 \%$ & $15 \%$ & $\mathbf{4 8 \%}$ & $21 \%$ \\
\hline $\begin{array}{l}\text { I was more motivated to attend classes } \\
\text { every week to do well on the leader-board. }\end{array}$ & $6 \%$ & $11 \%$ & $18 \%$ & $\mathbf{4 6 \%}$ & $19 \%$ \\
\hline $\begin{array}{l}\text { A high ranking on the leader-board } \\
\text { increased my self-confidence. }\end{array}$ & $1 \%$ & $3 \%$ & $15 \%$ & $\mathbf{5 6 \%}$ & $25 \%$ \\
\hline $\begin{array}{l}\text { I would find it more motivating if a high } \\
\text { ranking on the leader-board were rewarded } \\
\text { by the College. }\end{array}$ & $10 \%$ & $10 \%$ & $\mathbf{3 7 \%}$ & $33 \%$ & $10 \%$ \\
\hline $\begin{array}{l}\text { I found the use of the leader-board } \\
\text { intimidating. }\end{array}$ & $\mathbf{4 7 \%}$ & $31 \%$ & $12 \%$ & $8 \%$ & $2 \%$ \\
\hline
\end{tabular}

\section{Conclusions}

Based on the research results, it is evident that students attended classes more regularly during the 2018/19 school year as compared with the students' attendance in the previous year (first year of the experiment). It can, therefore, be stated that gamification motivated students to attend classes as regularly as possible. Students need to be aware that their attendance at lectures and exercises has a purpose, it is not only to satisfy a form. Instead, classes represent a time 
period that can be spent usefully by acquiring and confirming the knowledge and skills necessary for their success during studies as well as in the jobs they will take after graduation.

The proposed system for tracking class attendance automates, accelerates and digitizes the collected data and is useful for an educational institution and its students, as well. Points of interest include the following:

Through the gamification techniques and elements, apart from educational success (grades), the student is also given an opportunity to show off his or her characteristics, skills, abilities, etc. Gamification as a tool is aimed at motivating the student to actively participate in his or her own educational process.

The field of gamification is new and has yet to be fully researched. Motivation, both intrinsic and extrinsic, is a key factor in the success of students at all stages of their education. There are many motivating methods that could be implemented in education. The proposed system can be crucial in providing and encouraging students' motivation. For example:

- Give students a sense of control: this will allow them to define the priorities and to choose how to achieve the goals.

- Define the objectives: students always know how to acquire points and be better ranked on the list.

- Use positive competition: it can motivate students to try harder, to learn more just to be better ranked from the others.

- Offer rewards: through ranking on the leader-board and collecting badges, students get rewards. Those who contribute better, gain reward(s) and better ranking. Encouragement is the best way of motivating!

- Give students responsibility: what will be his/her ranking, which badges will stand beside his/her name depends only on how active the student is. The transferred responsibility can motivate the student.

- Make your classes exciting: Students must continuously be active or to attend to classes, because he/she will lose the position on the leader-board, or someone else will collect more badges.

- Make goals high, but attainable: Every student is aware of the fact that through attendance and contribution in class activities they can achieve a good position on the leader-board.

- Give feedback: The points, the badges and the position on the leader-board are the feedback for the student. Through them, the students can see if they are doing well, or if they should try to improve something.

- Track progress: The points, the badges and the position on the leader-board present the student's activity in real-time. 
- Make things fun: collecting badges and points are some kind of play. Competition with colleagues through playing makes this process fun.

- Provide opportunities for success: the presented system offers two ways for improving position on the leader-board. Firstly, the student collects points by attending classes. More attendance means more points. For the students who prefer different ways of learning, for example through the Internet, there is an opportunity to earn point simply by being active. This includes participating in competitions or doing extra projects, or by being active in class, the student can compensate for points that were lost by not attending every class.

The presented results and analyzes fits well in the field of CogInfoCom based education [25] and raises many of its applications in a variety of related research such as human-computer interfaces [26] and virtual or augmented reality supported learning [27, 28] or serious games and team based collaborative education [29-32] or cognitive abilities [33-37] for example.

\section{References}

[1] Coertjens, L., Brahm, T., Trautwein, C., \& Lindblom-Ylänne, S. Students' transition into higher education from an international perspective. Higher Education, 2017, 73(3), 357-369

[2] Brahm, T., Jenert, T., \& Wagner, D. The crucial first year: a longitudinal study of students' motivational development at a Swiss Business School. Higher Education, 2017, 73(3), 459-478

[3] Credé, M., Roch, S. G., \& Kieszczynka, U. M. Class attendance in college: a meta-analytic review of the relationship of class attendance with grades and student characteristics. Review of Educational Research, 2010, 80(2), 272-295

[4] Moore, R., Jensen, M., Hatch, J., Duranczyk, I., Staats, S., \& Koch, L. Showing up: the importance of class attendance for academic success in introductory science courses. The American Biology Teacher, 2003, 65(5), 325-329

[5] Trotter, E., \& Roberts, C. A. Enhancing the early student experience. Higher Education Research and Development, 2006, 25(4), 371-386

[6] Bruinsma, M., \& Jansen, E. P. W. A. When will I succeed in my first-year diploma? Survival analysis in Dutch higher education. Higher Education Research and Development, 28(1), 2009, 99-114

[7] Briggs, A. R. J., Clark, J., \& Hall, I. Building bridges: understanding student transition to university. Quality in Higher Education, 2012, 18(1), 3-21

[8] Bevitt, D., Baldwin, C., \& Calvert, J. Intervening early: attendance and performance as a trigger for first year support in the biosciences. Bioscience Education, 15(1), 2010 1-14 
[9] Woodfield, R., Jessop, D., \& McMillan, L. Gender differences in undergraduate attendance rates. Studies in Higher Education, 2006, 31(1), $1-22$

[10] Halpern, N. The impact of attendance and student characteristics on academic achievement: findings from an undergraduate business management module, Journal of Further and Higher Education, Pages 335349,2010

[11] Eisen, D. B., Schupp, C. W., Isseroff, R. R., Ibrahimi, O. A., Ledo, L., \& Armstrong, A. W. Does class attendance matter? Results from a secondyear medical school dermatology cohort study. International Journal of Dermatology, 2015, 54(7), 807-816

[12] Bevitt, D., Baldwin, C., \& Calvert, J. Intervening early: attendance and performance as a trigger for first year support in the biosciences. Bioscience Education, 15(1), 2010, 1-14

[13] St. Clair, K. L. A case against compulsory class attendance policies in higher education. Innovative Higher Education, 23(3), 1999, 171-180

[14] Ryan R, Deci E. Intrinsic and Extrinsic Motivations: Classic Definitions and New Directions Contemporary Educational Psychology 25, 2000, 5467, doi:10.1006/ceps.1999.1020

[15] Ryan, R. M., \& Stiller, J. The social contexts of internalization: Parent and teacher influences on autonomy, motivation and learning. In P. R. Pintrich\& M. L. Maehr (Eds.), Advances in motivation and achievement 1991, (Vol. 7, pp. 115-149) Greenwich, CT: JAI Press

[16] Demeter Robert, et al:, A quantitative study of using Cisco Packet Tracer simulation software to improve IT students' creativity and outcomes, $10^{\text {th }}$ IEEE International Conference on Cognitive Infocommunications, 2019, pp. 353-358

[17] J. Katona, A. Kovari: The Evaluation of BCI and PEBL-based Attention Tests, ActaPolytechnicaHungarica, 2018, Vol. 15, No. 3, pp. 225-249

[18] Mishra, R., \& Kotecha, K. Students engagement through gamification in education gamifying formative assessment. Journal of Engineering Education Transformations. http://dx.doi.org/10.16920/jeet/2017/v0i0/ 111751, 2017, ISSN 2394-1707

[19] Barna, B., \& Fodor, S. An empirical study on the use of gamification on IT courses at higher education. Teaching and learning in a digital world, 2017, (pp. 684-692) Cham: Springer. https://doi.org/10.1007/978-3-319-732107_80

[20] Buckley, P., \& Doyle, E. Individualising gamification: An investigation of the impact of learning styles and personality traits on the efficacy of 
gamification using a prediction market. Computers \& Education, 2017, 106, 43-55, https://doi.org/10.1016/j.compedu.2016.11.009

[21] D. Deugo, "Attendance Tracking," The $9^{\text {th }}$ International Conference on Frontiers in Education: Computer Science and Computer Engineering (FECS 2013), 2013, pp. 79-85

[22] Creatrix Campus, "Top 10 advantages of automated student attendance system," 2015 [Online] http://www.creatrixcampus.com/blog/top-10advantages-automated-student-attendance-system\#sthash.2LjXa4Cg.dpuf

[23] M. C. O'Connor, "Northern Arizona University to Use Existing RFID Student Cards for Attendance Tracking," [Online] May 24, 2010, http://www.rfidjournal.com/articles/view?7628

[24] L. Hakulinen, T. Auvinen and A. Korhonen, The Effect of Achievement Badges on Students' Behavior: An Empirical Study in a University-Level Computer Science Course, iJET - Volume 10, Issue 1, 2015, pp. 18-29, https://online-journals.org/index.php/i-jet/article/viewFile/4221/3394)

[25] A. Kovari: CogInfoCom Supported Education: A review of CogInfoCom based conference papers, Proceedings of the $9^{\text {th }}$ IEEE International Conference on Cognitive Infocommunications (CogInfoCom) 2018, pp. 233-236

[26] GergelySziladi, et al.: The analysis of hand gesture based cursor position control during solve an IT related task, $8^{\text {th }}$ IEEE International Conference on Cognitive Infocommunications, 2017. pp. 413-418

[27] L. Bognar, E. Fancsikne, P. Horvath, A. Joos, B. Nagy, GyorgyiStrauber: Improved learning environment for calculus courses, Journal of Applied Technical and Educational Sciences, Vol. 8, No. 4, 2018, pp. 35-43

[28] Cs. Szabó, Š. Korečko, B. Sobota: Data Processing for Virtual Reality: Advances in Robotics and Virtual Reality: Intelligent Systems Reference Library, Volume 26, Heidelberg : Springer-Verlag, 2012, pp. 333-361

[29] I. Heldal, C. Helgesen: The Digital HealthLab: Supporting Interdisciplinary Projects in Engineering and in Health Education, Journal of Applied Technical and Educational Sciences, Vol. 8, No. 4, 2018, pp. 4-21

[30] Cs. Rigóczki, A. Damsa, K. Györgyi-Ambró: Gamification on the edge of educational sciences and pedagogical methodologies, Journal of Applied Technical and Educational Sciences, Vol. 7, No. 4, 2017, pp. 79-88

[31] V. Szabóova, Cs. Szabó, V. Novitzká, E. Demeterová: Game semantics of the transaction rollback database operation, ActaElectrotechnica et Informatica. Vol. 15, No. 1, 2015, pp. 3-8

[32] I. Horváth: The IT device demand of edu-coaching in the higher education of engineering, $8^{\text {th }} \quad$ International Conference on CognitiveInfoCommunications, 2017. pp. 379-384 
[33] R. Pinter, S. M. Cisar: Measuring Team Member Performance in Project Based Learning, Journal of Applied Technical and Educational Sciences, Vol. 8, No. 4, 2018, pp. 22-34

[34] E. Gogh, A. Kovari: Metacognition and Lifelong Learning: A survey of secondary school students, $9^{\text {th }}$ IEEE International Conference on Cognitive Infocommunications, 2018, pp. 271-276

[35] T. Ujbanyi, et al: ICT Based Interactive and Smart Technologies in Education-Teaching Difficulties. International Journal of Management and Applied Science, 2017, 3.10: 72-77

[36] I. Fürstner, L. Gogolák, and P. Sarcevic: Development of telepresence technology during the teaching process at Subotica Tech, Journal of Applied Technical and Educational Sciences, Vol. 8, No. 4, 2018, pp. 44-53

[37] Peter Baranyi, Adam Csapo, Gyula Sallai, Cognitive Infocommunications (CogInfoCom), Springer International Publishing Switzerland, 2015, p. 219

[38] E. Gogh, et al.: Examining the relationship between lifelong learning and language learning in a vocational training institution, Journal of Applied Technical and Educational Sciences, Vol. 8, No. 1, 2018, pp. 52-69 